\title{
El cuerpo como espacialidad ambigua: Somato-política y resistencias corporales en Michel Foucault
}

\author{
The body as ambiguous spatiality: \\ Michel Foucault, politics and resistances of the bodies
}

ALEXANDER BENAVIDES FRANCO*

\begin{abstract}
Resumen: El cuerpo, en tanto punto de apoyo de las técnicas de poder para la configuración de los sujetos, posee, en la perspectiva foucaultiana, un estatuto complejo: es instrumento a la vez que efecto del poder. Apoyándose en él, el poder avanza; pero al tiempo que es atravesado por el poder, resulta a su vez, inscrito en un espacio de inteligibilidad determinado, investido de una cierta "interioridad" que lo espacializa y lo hace objeto de la mirada. El soporte del poder deviene efecto, pero no deja de ser soporte. El efecto es la forma como el soporte resulta investido por las operaciones del poder sobre él.
\end{abstract}

Palabras clave: Cuerpo, espacio ambiguo, desdoblamiento del cuerpo, heterotopía.

\begin{abstract}
Body, from the Foucault's perspective, is a supporting point of the power techniques in order to configure the subjects. That's the reason why it has a complex statute: It is both the means and the effect of power. In a certain way, body allows the advance of power, but at the same time it gets caught in a given space of intelligibility, and invested with some kind of "interiority" which spatializes it, and makes it object of the gaze. In this way, the supporting point becomes effect, but remains supporting point. The effect is thus the way the supporting point gets invested by the power moves.
\end{abstract}

Keywords: body, ambiguous space, unfolding of the body, heterotopy.

\section{Introducción}

Si el ejercicio del poder es para Foucault fundamentalmente físico, es porque su "objeto" de aplicación es siempre el cuerpo. El propio Foucault afirmó alguna vez que su posición era más materialista que la del marxismo, puesto que examinaba los efectos del poder al nivel del cuerpo mismo, y no de la ideología. Sin embargo, y a pesar del mencionado énfasis en los efectos materiales y físicos del poder, para Foucault dicha materialidad del cuerpo solo

Fecha de recepción: 23/05/2016. Fecha de aceptación: 17/07/2016.

* Universidade Federal do Rio Grande do Sul, UFRGS - Porto Alegre. Doctorando, Programa de Pós Graduação em Educação. Correo electrónico: abenavida@gmail.com Líneas de investigación: Estudios foucaultianos y Educación; Diferencia, alteridad y Educación; Escuela, poder y subjetividades. Publicaciones: "La filosofía como experiencia erótica en el Banquete de Platón". En: Humanizarte. No. 11. "La fílosofía como actitud existencial". En: Humanizarte. No. 14. 
es conocida a través del filtro de un determinado discurso vinculado a unas ciertas relaciones de poder. A este fenómeno se puede hacer alusión empleando la idea de un "desdoblamiento" del cuerpo como forma bajo la cual se hace visible e inteligible la materialidad indefinible de la corporeidad.

Dicha noción, tomada de la metáfora de Kantorowitz de los “dos cuerpos del rey", y de la cual hace uso Foucault en Vigilar y Castigar, permite dar cuenta de la forma cómo puede entenderse la construcción cultural del cuerpo foucaultiano. Está asociada por supuesto, al privilegio que, en su obra, Foucault concede a la mirada- a los dispositivos visuales- y al espacio, entendido aquí como el campo de visibilidad que configura esa mirada. Así, por ejemplo, puede constatarse que, tanto en El nacimiento de la clínica como en Vigilar y castigar, un dispositivo óptico, un aparato de visibilidad, opera en la constitución del cuerpo. Es decir que tanto la mirada clínica como la mirada panóptica hacen visible al cuerpo, y lo circunscriben en un espacio de inteligibilidad. Esto querría decir que aquello que se visibiliza no es un cuerpo prediscursivo, sino un cuerpo "otro" que se configura "sobre" lo que Foucault denomina la singularidad somática (2007a).

Por su parte, ese cuerpo otro podría entenderse como un cuerpo incorpóreo, una cierta virtualidad que viene a investir a la singularidad somática y a hacerla así objeto de la mirada. Ese incorpóreo no es otro que aquello que Foucault denomina el "alma moderna"la subjetividad o identidad- y que sería, paradójicamente, condición del aparecer de la corporeidad. En suma, la idea de desdoblamiento implicaría una "materialidad" corporal que solo puede conocerse en un determinado espacio abierto por el discurso. Pero esa virtualidad configurada "sobre" el cuerpo no se fija de manera inequívoca y absoluta, dado que la convergencia de regímenes discursivos, no siempre compatibles, ocasiona eventualmente complejidades discursivas que impiden una espacialización única y definitiva del cuerpo. El espacio discursivamente configurado del cuerpo deviene así espacio ambiguo, inestable, susceptible siempre de reconfiguración, y por ello mismo, resistente a las operaciones del poder.

\section{El cuerpo como espacio}

Es conocido el poderoso sentido de la historia que conduce a Foucault a ocuparse de cuestiones generales analizando momentos y experiencias específicos. Pero la historia de Foucault no consiste en el anhelo de retorno a un pasado mítico, ni el sueño de los orígenes, ni mucho menos una reconfortante visión de la trascendencia. Tal como apunta Felix Driver, "en lugar de una historia continua, centrada en el sujeto, propuso una historia descentrada, una historia como espacio de dispersión" (Driver, 1998, 114). La idea era escribir una historia sin sujeto trascendental. Una historia que dé cuenta de la constitución del sujeto, así como también de la constitución de conocimientos, discursos y prácticas. De acuerdo con Driver, es posible caracterizar muchas de esas investigaciones históricas foucaultianas como mapas más que como historias; como una cartografía de una nueva clase.

Driver señala cómo el propio Foucault recurrió constantemente a través de su obra al lenguaje del espacio: en el énfasis puesto en exclusiones y fronteras en La historia de la locura, espacios médicos y sociales en El nacimiento de la clínica, espacios discursivos en La arqueología del saber, y diagramas o figuras de poder en Vigilar y castigar. Pero también 
en textos como Cuestiones sobre geografía (1980), Espacio, conocimiento y poder (1984), De los espacios otros (1986), El ojo del poder (1980), o Le langage de l'espace (1964), los cuales atestiguan el interés directo de Foucault por la temática del espacio.

Podría decirse que, en cierto sentido, la discusión foucaultiana pretende repensar lo social a la luz del espacio, puesto que en el desvelamiento que propone el pensador francés, los dispositivos de control y las prácticas de poder cruzan claramente estratos espaciales.

De acuerdo con Driver, los conceptos espaciales permiten un análisis de las relaciones de poder en términos de encuentros estratégicos, batallas, terrenos y colonizaciones. Y aunque Foucault posiblemente encontró dichos términos útiles como metáforas, su importancia parece ir más allá de lo metafórico, dado que ponen de relieve el rol central del cuerpo, o más bien, de los cuerpos, en las relaciones de poder: "Foucault creyó que el espacio es fundamental en cualquier ejercicio del poder principalmente porque consideró el control de los cuerpos como fundamental" (Driver, 1998, 116). Pero más que permitir acceder a los cuerpos en un espacio dado, el lenguaje de la espacialidad permite acceder al cuerpo en tanto que espacio atravesado por relaciones de poder y saber, puesto que estas "topologizan" la materialidad del cuerpo.

Para precisar de qué manera la cuestión del espacio permite una mejor comprensión de la idea de cuerpo en Foucault, habrá que empezar por examinar en qué sentido las relaciones de poder, tal como el pensador francés las entiende, son productivas. En efecto, Foucault formula el poder como productor de realidad antes que como represor, y como productor de verdad antes que de ideología -“el poder produce, produce realidad; produce dominios de objetos y rituales de verdad"-; y además, afirma que el ejercicio del poder siempre acompaña la formación de saber: "no es posible que el poder se ejerza sin el saber, es imposible que el saber no engendre poder" (Foucault, 2006, 76). Esa articulación del poder con el saber permite en cada momento histórico una cierta configuración del ver y el decir que permite la producción de realidades; en otras palabras, se da un cierto reparto de lo visible y lo enunciable: se ve en función de las condiciones de visibilidad que dichas relaciones de poder-saber permiten, y se dice en función de sus condiciones de enunciación. Y aunque, tal como lo señalan Francisco Tirado y Martín Mora (2002), entre estas dos instancias no existiría necesariamente isomorfismo ni conformidad-en la medida en que no habría un hilo que transite de lo enunciable a lo visible- el poder tendría la potestad de co-adaptar una y otra, y en esa capacidad radicaría la productividad del poder.

Tirado y Mora aducen que para comprender adecuadamente la naturaleza de tal operación habría que recurrir a la acepción original de la palabra "producción", la cual no haría referencia tanto a la idea de fabricación material, sino más bien a la idea de hacer visible, de hacer aparecer y comparecer, exhibir y mostrar ${ }^{1}$. En esa medida, el poder productivo sería aquel que "opera liberando las cosas en el terreno de la visión, exponiéndolas ante la mirada, sustrayéndolas al secreto y a la oscuridad para arrojarlas a la luz, ante el ojo, delante del ojo" (Tirado y Mora, 2002, 19). El poder es entonces exposición, pero esta, según los mencionados autores, ha de entenderse como la creación de un plano que "espacializa" el pensamiento, y en especial, el orden de las cosas; la creación por lo tanto de un espacio. Así

1 Efectivamente, la palabra producir proviene del prefijo pro: adelante; y el verbo dulcere: guiar, conducir. Lo que literalmente significaría: conducir adelante, mostrar. 
pues, "no basta con afirmar que el poder, al articular visión y enunciado, se torna productivo. Hay que esclarecer que su acción es generación de espacio" (Tirado y Mora, 2002, 19).

Ahora bien, cabe aclarar que no se trata de un espacio imaginario ni de un recurso metodológico o de una simple creación epistemológica. Se trata de un espacio real, como real es el conjunto de cosas, enunciados, prácticas, poderes y saberes que lo constituyen y que él determina. El propio Foucault, aludiendo a las formas de espacialización que dieron paso a la historia natural y a las clasificaciones de Linneo, afirmó: "Éstas son técnicas de espacio, y no metáforas" (Foucault, 2010, 108). De manera que las relaciones espaciales que figuran en los trabajos de Foucault, no aluden tan sólo a geometrías formales, sino también y principalmente, a una serie de geografías "reales" que se visibilizan gracias al entrecruzamiento de relaciones de poder-saber muy particulares. Justamente, una de esas "geografías" es el cuerpo. Este constituye una "espacialidad" en la que confluyen por excelencia las relaciones de poder-saber, por encima incluso, del propio espacio geográfico: "poder y conocimiento operan en el espacio del cuerpo, no en el de la geografía" (Como se cita en: Driver, 1998, 98).

Pero ya desde Las palabras y las cosas, publicado en 1966, es decir, durante su periodo arqueológico, Foucault había concebido la espacialización del cuerpo. Allí, a propósito del descubrimiento -podría decirse espacialización- de la finitud que se daría en el "espacio" de la episteme moderna, Foucault afirma que dicha finitud estaría marcada "por la espacialidad del cuerpo, por el hueco del deseo y el tiempo del lenguaje" (Foucault, 2007b, 306; énfasis mío). Una nueva relación entre las palabras y las cosas- entre lo enunciable y lo visible- que configura el espacio de saber de la modernidad, visibiliza la finitud del hombre y la asigna al espacio de su corporalidad. Pero no se trata de una espacialidad cerrada sobre sí y acabada, definida de una vez y para siempre por una tensión de fuerzas ya resuelta. Más bien, habría que pensar en la modalidad de un espacio inestable, que se configura cada vez de manera diferente y que no puede pensarse si no es articulado con los otros objetos que el poder-saber espacializa. El cuerpo, en suma, es concebido aquí por Foucault como un "fragmento de espacio ambiguo, cuya espacialidad propia e irreductible se articula, sin embargo, sobre el espacio de las cosas" (Foucault, 2007b, 306). Que se trate de una espacialidad "propia" e "irreductible" parece dar cuenta de que el cuerpo es un espacio que se configura siempre de manera singular, pero nunca de forma estable o permanente. Que se articule sobre el espacio de las cosas implica que esa espacialidad que es el cuerpo resulta inseparable del espacio de saber que caracteriza el momento histórico en el que se halla inserto.

Pero toda una "topología" del cuerpo que expresa una compleja tensión entre lo irreductible y lo ambiguo de dicho espacio, se articula más claramente en una conferencia de Foucault pronunciada el mismo año de la publicación de Las palabras y las cosas. Dicha conferencia fue titulada por su autor como "El cuerpo utópico" (2010). Allí, Foucault parecería vacilar entre la idea de cuerpo como "lugar absoluto" y el cuerpo como "lugar sin lugar", como lugar que "siempre está en otra parte". Pero dicha vacilación no es más que otra forma de articular la noción de desdoblamiento o duplicación del cuerpo de la que se habló ya anteriormente.

El texto mencionado empieza caracterizando el cuerpo como el lugar del que no se puede escapar. No es posible desplazarse sin él, ni dejarlo en donde se encuentra para ir sin él a 
otro lugar. Está siempre allí, en el espacio que él mismo ocupa, nunca en otra parte: "Mi cuerpo es lo contrario de una utopía, lo que nunca está bajo otro cielo, es el lugar absoluto, el pequeño fragmento de espacio con el cual, en sentido estricto, yo me corporizo. Mi cuerpo, topía despiadada [...]" (Foucault, 2010,7). Se trata de ese carácter irreductible que permite hablar del cuerpo como algo propio; que permite decir "mi cuerpo" sin saber muy bien quizá de qué se está hablando exactamente, sin llegar a entender del todo que ese espacio cuya irreductibilidad parece inexorable es también absolutamente ambiguo. Porque no es un datum, aunque sea el lugar desde el cual el hombre finito de la modernidad experimenta el tiempo de la cultura y el espacio de las otras cosas. Porque está siendo siempre borrado y desaparece siempre para que aparezca otro lugar en su lugar; para darle paso a la utopía: "Después de todo, creo que es contra él y como para borrarlo por lo que se hicieron nacer todas esas utopías [...] La utopía es un lugar fuera de todos los lugares, pero es un lugar donde tendré un cuerpo sin cuerpo" (Foucault, 2010, 8).

Prefigurando lo que años más tarde diría en Vigilar y Castigar sobre la fijación de un cuerpo incorpóreo como efecto de cierta tecnología de poder sobre el cuerpo, Foucault afirma aquí que precisamente esa utopía primera encargada de borrar el cuerpo, aquella que habría echado sus raíces muy hondo en el corazón de los hombres, sería la utopía de un cuerpo incorpóreo, que inmediatamente pasa asociar con el alma: "pero tal vez la más obstinada, la más poderosa de esas utopías por las cuales borramos la triste topología del cuerpo nos la suministra el gran mito del alma, desde el fondo de la historia occidental" (Foucault, 2010, 9). Foucault señala además que esa alma durará largo tiempo e incluso más, cuando ya el viejo cuerpo decaiga, tal como el cuerpo intangible del rey permanece y asegura la estabilidad de su reino, aun cuando su singularidad somática deba perecer. El alma, cuerpo incorpóreo, cuerpo utópico, viene a fijarse en la singularidad somática que de otra forma no sería visible ni pensable. Y es que el cuerpo no puede ser pensado ni visibilizado sino es en su desdoblamiento, en su duplicación: "[...] ese mismo cuerpo que es tan visible, es retirado, es captado por una suerte de invisibilidad de la que jamás puedo separarlo" (Foucault, 2010, 11).

Parece no haber más cuerpo que el "alma". El "alma" es el cuerpo, materializa al cuerpo; no se puede concebir el cuerpo sino a través de ese fantasma que es el alma. El alma es la utopía. Siendo la utopía que se fija en el cuerpo, que viene a ocupar el lugar del cuerpo, "topologiza" su materialidad, lo instala en su despiadada pero siempre ambigua topología. Puede entenderse porqué Foucault ha dicho en otro lugar que "el alma es la prisión del cuerpo": es que la espacialidad del cuerpo no puede escapar de ese fantasma, de esa utopía que es el alma moderna. Foucault ha caracterizado inicialmente al cuerpo como una topía despiadada. Finalmente, parece retractarse cuando afirma: "Realmente era necio, hace un rato, de creer que el cuerpo nunca estaba en otra parte, que era un aquí irremediable y que se oponía a toda utopía". Y a renglón seguido: "Mi cuerpo, de hecho, está siempre en otra parte, está ligado a todas las partes del mundo, y a decir verdad está en otra parte que en el mundo" (Foucault, 2010, 16). Pero su vacilación ha sido premeditada. Se trataba de marcar la inseparabilidad de lo irreductible y lo ambiguo del espacio del cuerpo, de pensar el cuerpo en su ineludible desdoblamiento: al final, la singularidad somática parece borrarse y confundirse ya siempre con el alma, con la utopía, con ese cuerpo incorpóreo que de todas formas la configura como espacio. 


\section{El cuerpo como "heterotopía" y posibilidad de resistencia}

Pareciera que, en última instancia, no fuera posible escapar de la sujeción o resistir a ella. Pareciera que Foucault se limita a presentar un panorama desolador en el que el sujeto es configurado inexorablemente por un poder político que se fija en él y que no deja espacio para ser de otra manera. Sin embargo, el propio Foucault se ocupa de esta dificultad en el que se considera el último periodo de su obra intelectual. Es así como el pensador francés deja en claro que el tema del sujeto constituyó siempre su preocupación fundamental y que lo que hasta el momento había rechazado no era otra cosa que una teoría a priori del sujeto; la idea del sujeto como una sustancia (Foucault, 1999).

De manera pues que el sujeto se constituye, a decir de Foucault, siempre en relación con unos determinados "juegos de verdad" y unas ciertas prácticas de poder. De acuerdo con el tipo de relaciones que en ese proceso se establezcan, dicha constitución resultaría sujetante o no. Pero un sujeto no resulta constituido de una manera definitiva, pues a cada momento se encuentra atravesado por relaciones de poder-saber que no son siempre las mismas. En esa medida, el sujeto

[...] es una forma y esa forma no es ni ante todo ni siempre idéntica a sí misma. Ustedes, por ejemplo, no tienen respecto de ustedes mismos el mismo tipo de relaciones cuando se constituyen como sujeto político que va a votar o que toma la palabra en una asamblea, que cuando buscan realizar su deseo en una relación sexual. Hay sin duda relaciones e interferencias entre estas diferentes formas de sujeto, pero no estamos en presencia del mismo tipo de sujeto (Foucault, 1999, 403).

Ello es posible, dado que las relaciones de poder al interior de las cuales se configura el sujeto se pueden encontrar, según el propio Foucault, en diferentes niveles, bajo formas diferentes; son relaciones móviles, reversibles e inestables, y por ello, no están dadas de una vez por todas. Dicha caracterización de las relaciones de poder presupone, en la perspectiva foucaultiana, la libertad de los sujetos y en esa medida, también la posibilidad de la resistencia, ya que como el mismo Foucault lo ha dicho, si no existiera tal posibilidad, sencillamente no existirían relaciones de poder. No tiene sentido, por lo tanto, para el filósofo francés, la objeción que tantas veces se le habría planteado, según la cual, si el poder está en todas partes entonces no habría libertad. A dicha objeción Foucault responde sencillamente: "si existen relaciones de poder a través de todo el campo social, es porque por todas partes hay libertad [...]. No se me puede atribuir la idea de que el poder es un sistema de dominación que lo controla todo y que no deja ningún espacio a la libertad" (Foucault, 1999, 406). De manera pues que no puede pensarse que los mecanismos de sujeción ejercen un condicionamiento absoluto, sino que permiten una cierta ductilidad. Al parecer no logran fijar la función sujeto a la singularidad somática de manera definitiva, como Foucault pensaba en otro momento, puesto que en esos mismos mecanismos vienen dadas las condiciones de excedencia de la sujeción.

A la luz de lo dicho, la idea de un sujeto que no es siempre el mismo puede ser perfectamente articulada con la idea de un cuerpo concebido como espacialidad ambigua. La fijación de una cierta función sujeto en el cuerpo -su desdoblamiento o duplicación- no 
es absoluta ni definitiva, en la medida en que se encuentra atravesado por relaciones de poder que no son siempre las mismas. El cuerpo del rey se desdobla como producto de relaciones de poder muy específicas, pero también el rey, con su cuerpo físico y a la vez intangible es decapitado en una configuración de relaciones diferente. En virtud de tales complejidades, otras utopías vendrán a fijarse en la singularidad somática; otros espacios tendrán lugar en el espacio ambiguo del cuerpo, permitiendo que este no resulte topologizado de una única forma.

Eventualmente, la incompatibilidad de dichos espacios permitiría una configuración distinta de la subjetividad, pero esto dependería, además, del tipo de relaciones que se establezcan con los juegos de verdad que en cada caso conducen a la conformación de esos espacios singulares. De manera pues que la espacialización misma del cuerpo trae consigo la posibilidad de su propia excedencia: Paradójicamente, junto con el espacio visible del cuerpo, una zona de invisibilidad se conformaría; tras la superficie, la ficción de una profundidad que guarda un secreto esperando ser develado. Así pues, ténganse en cuenta las palabras de Butler, acerca de lo que Foucault denomina el alma moderna: "una significación que produce sobre la carne la ilusión de una inefable profundidad" (Butler, 1989, 605). La utopía fijada al cuerpo constituiría, en su espacio de claridad, la identidad misma del sujeto; pero en su zona de oscuridad, en su "inefable profundidad", puede pensarse como ese "secreto" que invita perpetuamente a su propia construcción y que al ser así elaborado permanentemente al interior de regímenes discursivos que buscan afanosamente la sujeción de los cuerpos, conduciría paradójicamente a una eventual reconfiguración de la espacialidad bajo la cual tiene lugar la visibilización de los mismos. Ello, en la medida en que, como lo señala Buttler en The Psychic life of power (1997), a través de la convergencia de regímenes discursivos diversos, se producen inadvertidamente complejidades discursivas que "socavan las pretensiones teleológicas de la normalización" (Citado en: Oksala, 2004, 107). Es decir que esa ilusión de interioridad que sería inherente al espacio de visibilización del cuerpo, y que invita a su perpetua construcción discursiva, es configurada de formas no siempre compatibles bajo regímenes de saber diferentes.

En esa medida, la forma como a cada paso las relaciones de poder buscan investir al cuerpo discursivamente que, en principio busca ser sujetante, induciría paradójicamente a la desestabilización misma de la espacialización que se opera sobre el cuerpo. Como resultado, el espacio de visibilización del cuerpo no sería un espacio fijo y definitivo, sino ambiguo, inacabado, susceptible siempre de reconfiguración, y cuya inestabilidad sería producto de la dinámica misma de las relaciones de poder y del apresamiento siempre falible de los cuerpos por parte de los dispositivos del poder-saber. La ambigüedad del espacio así configurado se presenta entonces como la excedencia misma, lo que haría tambalear el desdoblamiento que allí tendría lugar, en la medida en que el secreto allí "guardado" invita a la vez a la construcción de nuevas utopías que, eventualmente, pueden resultar des-sujetantes: "Pero mi cuerpo, a decir verdad, no se deja someter con tanta facilidad. Después de todo, él mismo tiene sus recursos propios de lo fantástico; también el posee lugares sin lugar y lugares más profundos, más obstinados todavía que el alma [...]. Tiene sus bodegas y sus desvanes, tiene sus estadías oscuras, sus playas luminosas" (Foucault, 2010, 10).

Así, por ejemplo, en la configuración del cuerpo sexual, el dispositivo de la sexualidad genera la idea del sexo como una realidad siempre ambigua a la que se le debe arrancar su 
verdad mediante una puesta en discurso del deseo, que Foucault asocia con el mecanismo cristiano de la confesión. Es que el funcionamiento del sexo se presenta como algo oscuro, "porque está en su naturaleza escapar siempre, porque su energía y sus mecanismos se escabullen; porque su poder causal es en parte clandestino" (Foucault, 2006, 69). Se llega así a articular en una práctica científica la obligación de una confesión que permita arrancar al sexo esa verdad que esconde. Una verdad que es en última instancia, la verdad misma del sujeto, pero que no reside en el sujeto. Se constituye discursivamente. Y aunque la sociedad del siglo XVIII, habría puesto en acción todo un aparato para producir sobre el sexo discursos verdaderos, y se lanzó a la empresa de formular su verdad regulada, todo un espacio de invisibilidad se habría construido que, como en el caso anterior, constituiría la posibilidad de dislocación del cuerpo con esa sexualidad normativizada que lo fijaría al dispositivo. Otras elaboraciones de ese secreto serían posibles; otras utopías confluirían en el espacio del cuerpo sexual, que permitan visibilizar el cuerpo de otras maneras.

Ahora bien, en la medida en que el cuerpo en su ambigua espacialidad permite la confluencia de espacios diferentes, de utopías heteróclitas, deviene cuerpo heterotópico. Podemos definir el cuerpo como heterotopía. Esta, según Foucault, tendría por regla general, la yuxtaposición en un lugar real, de varios espacios que normalmente resultan ser incompatibles (Foucault, 2010, 25). Se trata de lugares que se oponen a todos los otros -contraespacios- superponiéndose a ellos, y que estarían destinados de algún modo "a borrarlos, a neutralizarlos o a purificarlos"; son, en otras palabras, "impugnaciones míticas y reales del espacio donde vivimos" (Foucault, 2010, 25). Foucault ofrece el ejemplo del teatro, en el que se suceden, sobre el rectángulo de la escena, toda una serie de lugares diferentes. Pero también serían heterotopías el fondo del jardín, la tienda de indios levantada en el desván y hasta la gran cama de los padres: "es sobre esa gran cama de donde se descubre el océano, porque uno puede nadar allí entre las mantas; y además, esa gran cama es también el cielo, ya que se puede saltar sobre los resortes; es el bosque, porque uno se esconde [...]" (Foucault, 2010, 20).

¿Porque no pensar entonces la heterotopía del cuerpo? En él tiene lugar la utopía del alma: "Es mi cuerpo luminoso, purificado, virtuoso, ágil, móvil, tibio, fresco; es mi cuerpo liso, castrado, redondeado como una burbuja de jabón" (Foucault, 2010, 10). Pero también, la máscara, el tatuaje y el afeite colocan al cuerpo en otro espacio, "hacen de ese cuerpo un fragmento de espacio imaginario que va a comunicar con el universo de las divinidades o del otro [...] son operaciones por las cuales el cuerpo es arrancado a su espacio propio y proyectado a otro espacio". Y si además se piensa en la vestimenta, sea esta sagrada o profana, religiosa o civil, "entonces se ve que todo cuanto toca al cuerpo -dibujo, color, diadema, tiara, vestimenta, uniforme-, todo eso hace alcanzar su pleno desarrollo [...] a las utopías selladas en el cuerpo" (Foucault, 2010, 10). El cuerpo, según Foucault, sería, en su materialidad, producto de sus propias fantasías: "después de todo, ¿acaso el cuerpo del bailarín no es justamente un cuerpo dilatado según todo un espacio que le es interior y exterior a la vez? Y también los drogados, y los poseídos; los poseídos, cuyo cuerpo se vuelve infierno; los estigmatizados, cuyo cuerpo se vuelve sufrimiento, redención y salvación, sangrante paraíso" (Foucault, 2010, 15). En última instancia, el cuerpo "es como la Ciudad del Sol, no tiene un lugar, pero de él salen e irradian todos los lugares posibles, reales o utópicos" (Foucault, 2010, 16). 
En virtud de esa condición heterotópica del cuerpo, este tendría siempre la posibilidad de resistir a cualquier tipo de espacialización sujetante. Es que las heterotopías son, según Foucault, la impugnación de todos los otros espacios. Pero, a decir del pensador francés, dicha impugnación puede ser ejercida de dos maneras: "o bien [...] creando la ilusión que denuncia todo el resto de la realidad como ilusión, o bien, por el contrario, creando realmente otro espacio real tan perfecto, tan meticuloso, tan arreglado como el nuestro es desordenado, mal dispuesto y confuso" (Foucault, 2010, 30). En cualquiera de los dos casos, se trata de un proceso de creación que implica no solo una relación muy particular con el propio cuerpo, sino, además, como ya se ha mencionado, con los juegos de verdad que determinan el espacio de la cultura.

\section{Conclusiones}

El poder que se introduce en el cuerpo y avanza a través de él, desdoblándolo, expandiéndolo, reconfigurándolo, se encuentra a su vez, expuesto en el cuerpo mismo. En esa difusión simultánea del cuerpo y del poder, al mismo tiempo que el poder avanza y multiplica sus estaciones de enlace y sus efectos, en el cuerpo se han formado zonas de opacidad, de impenetrabilidad, de invisibilidad. Al no tener un control absoluto de sus efectos sobre el cuerpo, las técnicas del poder permiten la configuración de un cierto espacio de indocilidad y de excedencia. Es así como ese mismo cuerpo que es efecto e instrumento de las operaciones del poder, resulta a la vez cuerpo resistente a esas mismas operaciones. Algo en él siempre escapa al proceso de desdoblamiento, que permite la aparición de puntos de resistencia a dicho proceso.

La pregunta por cómo pensar posibilidades de acción política en el marco de las técnicas de poder que se despliegan en las sociedades contemporáneas es una preocupación central en Foucault. Pero ¿cómo entender la importancia del cuerpo en el marco de esa cuestión más amplia? En último análisis, si puede considerarse a los individuos como cuerpos sujetados al interior de técnicas muy particulares de poder, las posibilidades de resistencia a tales formas de sujeción deberían pasar por pensar prácticas que posibiliten la des-sujeción del cuerpo y la creación de nuevas formas de existencia a partir de modalidades inéditas de relación con el mismo. En consecuencia, podría aseverarse, a partir de Foucault, que la tarea de pensar estrategias efectivas de resistencia frente a las técnicas y dispositivos del biopoder, debería situarse al nivel de lo que este invade: la vida misma y los cuerpos.

\section{Referencias}

Butler, Judith (1989): "Foucault and the paradox of bodily inscriptions", en: The Journal of Philosophy, Vol. 86, No. 11, Eighty-Sixth Annual Meeting American Philosophical Association, Eastern Division, pp. 601-607.

Driver, Felix. (1998): "Bodies in space”. En: Porter, Roy Jones, Colin (Comp.). Reassessing Foucault. Power, medicine and the body, Florence, KY, USA, Routledge.

Foucault, Michel (1983): Vigilar y Castigar, México/España/Argentina/Colombia, Siglo XXI Editores. 
Foucault, Michel (1999): La ética del cuidado de sí como práctica de la libertad, en: Estética, ética y hermenéutica. Obras esenciales, volumen III (pp. 393-416), traducción de Angel Gabilondo, Barcelona, Paidós.

Foucault, Michel (2006): La voluntad de saber, $10^{\mathrm{a}}$ Ed. Madrid, Siglo XXI.

Foucault, Michel (2007a): El poder psiquiátrico, Curso en el Collège de France (19731974), Buenos Aires, Fondo de Cultura Económica.

Foucault, Michel (2007b): Las palabras y las cosas, México/España/Argentina/Colombia, Siglo XXI Editores.

Foucault, Michel (2010): El cuerpo utópico. Las heterotopías, Buenos Aires, Nueva Visión.

Oksala, Johanna (2004): Anarquic bodies: Foucault and the feminist question of experience, en: Hypatia, vol. 19, No. 4, pp. 99-121.

Tirado, Francisco y MORA, Martín (2002): "El espacio y el poder: Michel Foucault y la crítica de la historia", en: Espiral, Estudios sobre Estado y Sociedad, Vol. 9, No 25, pp. 11-36. 